\title{
THE USE OF MOBILE ASSISTED LANGUAGE LEARNING APPLICATIONS IN LEARNING ARABIC
}

\author{
Dr. RazakW. Abedalla, California University of Pennsylvania, abedalla@calu.edu
}

\begin{abstract}
Mobile learning refers to the education that can be delivered through the use of mobile technologies. This type of education is convenient for educators and learners. It can be accessed anywhere at any time. Mobile application (app) is one of those technologies that designed for education purposes. Mobile learning is ubiquitous and can be done by using different types of devices, such as smart phones, handheld PCs, tablets, iPads, iPods, and PDAs. Since several small and portable devices can be used for mobile learning, this learning is mobile and allows the teachers and learners to continue learning and interaction beyond the traditional classroom limits. The Findings were that mobile assisted language learning (MALL) apps were helpful in learning Arabic.
\end{abstract}

Keywords: Arabic as a Second Language, Mobile Apps, Mobile Assisted Language Learning, Mobile Computing, Mobile Learning

\section{INTRODUCTION}

To date, learning a new language is a key discipline that benefitted from mobile learning [26]. The students do not need to sit in a classroom, as MALL is an ideal solution to language learning barriers in terms of time and location [31]. Students may face several challenges when it comes to learning a new foreign language. Educators may understand how learning a foreign language can be frustrating for people who do not speak that language, but they may not know how to end this frustration. In an effort to reduce this frustration, technology is used in learning methods in most foreign language classrooms. Although many learning techniques have been developed for several languages, such as English, Spanish, German, French, and Chinese [19], Arabic has fewer techniques available for enhancing learners' communication abilities. Thus, this research attempts to fill in the gap in the literature relating to the use of mobile apps technology to enhance the learning of Arabic.

Because of the current instable state of politics in the Arab world following the Arab Spring revolutions and the security issues, it has become crucial to learn more about this culture, history, and language. Arabic is known for its syntactic complexity, lexical sophistication, and variety of scripts and dialects. Because of the language barriers, unstable political situation in the Arab world, language characteristics, and lack of literature on using mobile apps technology to enhance the learning of Arabic, the researcher chose to focus on Arabic in the current study. The study attempts to answer the following research question: What are the American university students' perceptions of the use of mobile apps in learning Arabic?

\section{LITERATURE REVIEW}

\section{Arabic Language}

Arabic is among the six most spoken languages worldwide because it is considered the mother and official language of 22 countries. Arabic is also the language of Islam and is understood by over one billion Muslims around the world [8, 22]. Arabic is one of the Semitic languages (i.e., Hebrew or Amharic), which is "rich in its morphology and syntax" [39]. Semitic language refers to a large Afro-Asiatic language family and was named by A. L. Schloezer in 1781 to refer to the languages spoken by people among the sons of Sem [29]. Arabic preserved many of the features of the language predecessor, and the word "Arab" itself is derived from the Semitic root "nomad." In the Arabic language, the word "Arab" refers to those people who speak Arabic (i'rab) clearly, as contrasted with Ajam people who speak Farsi. Originally, Arabic was the language used by the itinerant tribes who lived in the desert of the Arabian Peninsula [33]. Figure 1 shows the Semitic languages: 


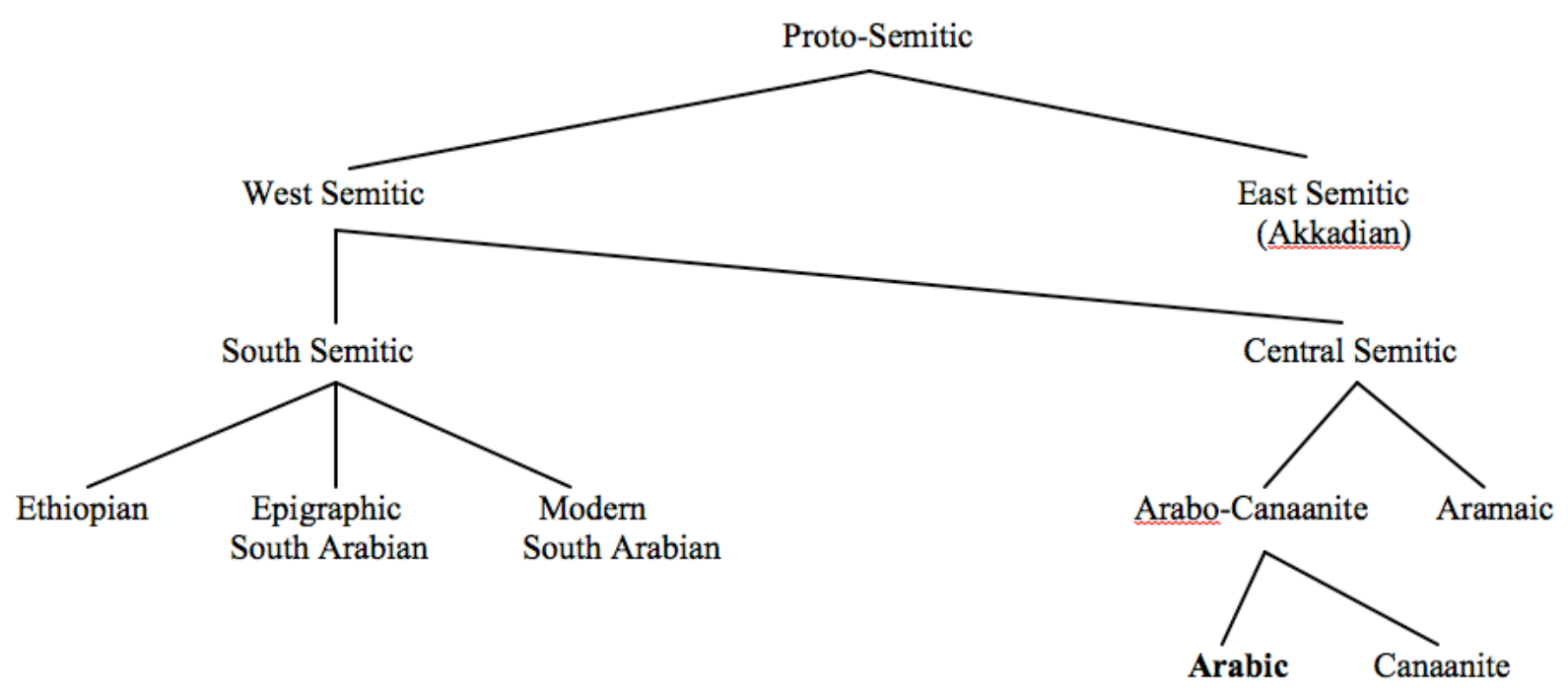

Figure 1. The Genealogy of the Semitic Languages [50]

In another way, Arabic diglossia refers to the "two varieties of the same language side-by-side in a speech community" [7]. Thus, the two varieties of the Arabic language are the informal, "colloquial," and the formal, "fusha." Colloquial is the spoken dialect by the Arabic region, such as Gulf, Egyptian, Levantine, Moroccan, etc. Fus-ha is the formal standard and official language that Arabs can use in more formal contexts, such as newspapers, magazines, TV shows, official documents, and textbooks [8,33].

As for the origin of the Arabic writing system, it descended from the Nabatean Aramaic script. As the Aramaic script requires a limited number of consonant letters for Arabic, the shapes of Arabic letters were extended by adding dots either above or below the letter to distinguish between one letter from another [50,17]. Arabic has 28 letters in the alphabet: three long vowels (alif, waw, yaa) and 25 consonants that have different shapes in the initial, medial, final, and individual positions of the word. There are short vowels indicated by optional diacritical markings, which are often not written. These markings are Dama, Kasra, and Fat-ha. The Arabic writing system is a cursive script from right to left. Six letters are non-connecters or one-way connectors, and 22 letters are connectors. Connectors are letters that can be connected with one another. The non-connecters or one-way connectors mean that the letters do not connect at all with other letters or do connect with one side depending on their position in the word [2].

\section{Technology and Language Learning}

Mobile devices have a strong grip on people and society [35]. Mobile apps technology is one of those technologies that have a strong impact on people. Mobile apps technology is defined as "a type of application software designed to run on a mobile device, such as a smartphone or tablet computer" [46]. Many mobile apps were developed to enhance communication and second language learning because of the increasing interest in learning world languages. Several studies, such as [23, 44, 47], showed that students had a strong motivation for learning languages via MALL apps.

Over the past 20 years, literature in the United States (US) shows there is a positive link between technology and classroom education. Several institutions adopted new approaches to communication and information technology (IT) to increase the learner's essential knowledge and to promote meaningful and effective learning [15]. In recent years, mobile technologies have supported the communication pedagogy because communication is considered a "central pillar" in learning world languages [45]. The emergence of mobile technologies attracted the interest of educators. Several other studies, such as $[3,9,13]$, showed that mobile technologies were effective in learning. Mobile technologies, specifically MALL technology, were increasingly integrated into the foreign-language curriculum in secondary and higher education settings [1]. Mobile devices have become part of our lives and they 
have become ubiquitous within our society as necessary tools to facilitate socio-cultural opportunities for learning $[12,32,34]$. Over time, mobile technology has changed our culture. For example, we see that receiving a phone call at dinnertime is now often considered to be communication and not interruption [37]. As of 2015, we live in a huge world that is becoming a small village because of the technology. "People are staying 'plugged-in' and connected to what has become an 'always on' world" [36].

In his several studies on mobile technologies, Kukulska-Hulme [28] indicated that mobile technologies have the advantage of "anywhere and anytime," which supported the idea of adapting MALL in educational contexts to engage students' learning abilities. However, it has to be known that mobile technologies are only supplemental and instructional tools for enhancing communication and improving language instructions; they are not to replace the role of the instructor. Mobile technologies are very important to facilitate the learning process, but their effectiveness depends on the existence of a successful instructor who has good pedagogical knowledge and effective teaching practices [25]. Chinnery [14] also argued that mobile technologies are very useful in language learning but that they cannot function as replacement for the classroom instructor.

Moreover, several studies such as, [24, 41, 42,38] claimed that the use of mobile apps technology makes learning fun, valuable, and collaborative. Literature showed that the use of mobile apps in learning was useful [6, 25, 41]. Gilgen [20] and Shockoe [41] stated that mobile apps are user-friendly and interesting when they are used in language learning. The frequency of using mobile apps also helps the students in improving their language learning $[18,43,44]$. Since there are many apps, Abedalla [2] recommends that the selection and development of apps have to be based on the students' goals and ages. Literature also showed that there were no significant differences between the online and on-ground students $[4,11,48]$.

\section{Mobile Learning (m-Learning)}

Sharples et al. [40] define mobile learning (m-Learning) as a "process of coming to know through conversations across multiple contexts among people and personal interactive technologies" (p. 225). Mobile assisted language learning (MALL) is a newly emerging approach in learning modern languages. The term MALL is a subset of both mobile learning (m-Learning) and computer assisted language learning (CALL). It "describes an approach to language learning that is assisted or enhanced through the use of a handheld mobile device" [49]. It refers to the use of mobile technologies as supplemental tools to enhance language learning [51]. MALL is a branch of technology, which enhances the process of learning in many forms including "face-to-face" and "distant or on-line modes" [9].

The principle of m-Learning is "anytime, anywhere" [27]. Mobile devices can also "support language learners in noticing and recording noticed features 'on the spot', to help them develop their second language system" [27]. The good thing about mobile devices is that they increase efficiency and decrease costs for academic institutions. The students can use their mobile devices to complete their assignments, such as language conversation recording, without making a trip to the computer lab to use a desktop computer. Learners can use mobile devices to learn in their own community so that they can tutor and help each other in the learning process [2]. "The learner is mobile and is at the center of the learning, and the technology allows the learner to learn in any context" [5]. Schools might think to develop mobile labs with limited funding as they are user-friendly and not costly [20]. "As in other technology-enhanced language learning milieu, mobile learning environments might be face-to-face, distance, or online; further, they may be self-paced or calendar-based" [14]. Mobile technologies could ease and simplify the process of learning. They could also support learning by extending the time and space limitations of the traditional classroom [21].

Mobile Learning Advantages. Mobile technologies have several advantages for educators and learners. One of the advantages is that the use of mobile devices is less expensive than having a computer lab for learning language purposes. The other advantage is that the mobile technologies convey information and services ubiquitously [53]. They are also portable, light, and convenient for learners to use outside the classroom practices and to facilitate remote participation $[28,31]$.

Mobile Learning Challenges. Despite its advantages, mobile technologies also have challenges, such as small screen sizes, limited audiovisual quality, limited presentation of graphics, one-finger data entry, and limited power 
$[10,14,30,49]$. Another challenge is that a "computer is better than a mobile phone for handling various types of information such as visual, sound, and textual information" [52].

\section{RESEARCH METHODOLOGY}

This research is a quantitative study and it focuses only on non-native speakers of Arabic who took Arabic classes at their universities for multiple different reasons such as the interest in learning the language and culture of the Arab world, future job purposes, or as a requirement to fulfill their majors and degrees. A quantitative (QUAN) research approach was used to examine the research problem. A questionnaire was developed by the researcher and was tested in a pilot study for validity and reliability. The questionnaire was used to measure the participant's perceptions about the impact of using mobile technology in learning Arabic as a modern language. One of the questionnaire questions was a rating question used a five-point Likert-type scale, with 1=Strongly Disagree (SD); 2=Disagree (D); 3=Neutral (N); 4=Agree (A); and 5=Strongly Agree (SA). The researcher administered the questionnaire as an online survey and a hard copy survey. The participants were 40 male and female American college students and they were recruited from different majors of study at different universities in USA. The participants agreed to participate in this study on a voluntary basis to share their perceptions the mobile learning approach. The questionnaire welcome statement also stated the amount of time estimate that would take participants to complete the questionnaire. The study followed the American Council on the Teaching of Foreign Languages (ACTFL) Five Cs standards model in learning foreign languages: Communication, Cultures, Communities, Comparisons, and Connections. Communication helps the students to communicate in a language other than English. Cultures help the students to obtain knowledge and understand other cultures. Connections help the students to connect with other disciplines and acquire more information about the foreign language. Comparisons category help the students to compare their native language and culture with the foreign language and culture. Communities category help the students can work with others in a multilingual environment at home and outside home. All the above Five Cs form the backbone of foreign language learning. They are all connected and work together in one circle as each $\mathrm{C}$ arrow complements the others, and they were tied in the survey questions to see how the MALL apps help the students learn Arabic. All the students used the same apps that were recommended by the instructor. The students' perceptions focused on the use of multiple MALL apps in learning Arabic and not on a specific app. The instructor gave the students different speaking scenarios to use the apps in their learning practices.

\section{RESULTS}

Statistical Package for the Social Science (SPSS Version 22) was used for analysis and to calculate the frequencies of the participants' responses. The results, in Table 1, show that $90 \%$ of the participants' ages were between 18-25 years old.

Table 1. Age

\begin{tabular}{|c|c|c|c|}
\hline Age Range & Frequency & Percent & Valid Percent \\
\hline $18-25$ & 36 & 90.0 & 90.0 \\
\hline $26-34$ & 3 & 7.5 & 7.5 \\
\hline $35-44$ & 1 & 2.5 & 2.5 \\
\hline
\end{tabular}

Table 2 exemplifies the participants' frequency of using the apps.

Table 2. Frequency of Using the Mobile Apps

\begin{tabular}{|l|c|c|c|}
\hline Using the mobile apps & Frequency & Percent & Valid Percent \\
\hline Very frequently & 5 & 12.5 & 12.5 \\
\hline Frequently & 13 & 32.5 & 32.5 \\
\hline Occasionally & 17 & 42.5 & 42.5 \\
\hline Rarely & 5 & 12.5 & 12.5 \\
\hline
\end{tabular}

The results showed that $95.0 \%$ (38 students) were undergraduate students and $5.0 \%$ (two students) were graduate students. As for the Arabic class format, 55.0\% (22 students) were on-ground (in-class) students and 45.0\% (18 students) were online students. 57.5\% (23 participants) were beginners in Arabic 101 and $42.5 \%$ (17 respondents) 
were high beginners in Arabic 102. 15.0\% (six students) were required to study Arabic for graduation, 25.0\% (10 students) studied it for job-related purposes, $50.0 \%$ (20 students) were interested in the language and culture, and $10.0 \%$ (four students) studied it for other reasons (such as religious reasons, a military career path, or leaving the question unanswered).

The results also showed that the majority of the participants' responses were between strongly agree and agree. The participants were satisfied with the method of using MALL in learning Arabic. The participants also reported that MALL were useful, user-friendly, and they could be accessed anywhere at any time. The participants also stated that they enjoyed the use of MALL apps in their learning activities. MALL apps helped them to interact with their classmates in-class and beyond the classroom. MALL apps also helped the students to improve their speaking skills. The following tables show the frequencies of students' responses to each question.

Table 3. I Am Satisfied With Using Mobile Apps for Arabic Learning

\begin{tabular}{|l|c|c|c|}
\hline \multicolumn{1}{|c|}{ Satisfaction } & Frequency & Percent & Valid Percent \\
\hline Strongly Agree & 15 & 37.5 & 37.5 \\
\hline Agree & 17 & 42.5 & 42.5 \\
\hline Neutral & 6 & 15.0 & 15.0 \\
\hline Disagree & 2 & 5.0 & 5.0 \\
\hline Strongly Disagree & 0 & 0 & 0 \\
\hline
\end{tabular}

Table 4. Apps Can Be Accessed At Anywhere At Any Time

\begin{tabular}{|l|c|c|c|}
\hline \multicolumn{1}{|c|}{ Access } & Frequency & Percent & Valid Percent \\
\hline Strongly Agree & 20 & 50.0 & 50.0 \\
\hline Agree & 14 & 35.0 & 35.0 \\
\hline Neutral & 3 & 7.5 & 7.5 \\
\hline Disagree & 2 & 5.0 & 5.0 \\
\hline Strongly Disagree & 1 & 2.5 & 2.5 \\
\hline
\end{tabular}

Table 5. Apps Are Useful in Learning Arabic

\begin{tabular}{|l|c|c|c|}
\hline \multicolumn{1}{|c|}{ Usefulness } & Frequency & Percent & Valid Percent \\
\hline Strongly Agree & 19 & 47.5 & 47.5 \\
\hline Agree & 17 & 42.5 & 42.5 \\
\hline Neutral & 3 & 7.5 & 7.5 \\
\hline Disagree & 1 & 2.5 & 2.5 \\
\hline Strongly Disagree & 0 & 0 & 0 \\
\hline
\end{tabular}

Table 6. Apps Are User-Friendly

\begin{tabular}{|l|c|c|c|}
\hline \multicolumn{1}{|c|}{ User-friendly } & Frequency & Percent & Valid Percent \\
\hline Strongly Agree & 12 & 30.0 & 30.0 \\
\hline Agree & 23 & 57.5 & 57.5 \\
\hline Neutral & 4 & 10.0 & 10.0 \\
\hline Disagree & 1 & 2.5 & 2.5 \\
\hline Strongly Disagree & 0 & 0 & 0 \\
\hline
\end{tabular}

Table 7. I Very Much Enjoyed Using the Mobile Apps in my Arabic Class This Semester

\begin{tabular}{|l|c|c|c|}
\hline \multicolumn{1}{|c|}{ Enjoyment } & Frequency & Percent & Valid Percent \\
\hline Strongly Agree & 12 & 30.0 & 30.0 \\
\hline Agree & 15 & 37.5 & 37.5 \\
\hline Neutral & 10 & 25.0 & 25.0 \\
\hline Disagree & 3 & 7.5 & 7.5 \\
\hline Strongly Disagree & 0 & 0 & 0 \\
\hline
\end{tabular}

Table 8. Apps Enhance My Communication Skills

\begin{tabular}{|l|c|c|c|}
\hline Communication & Frequency & Percent & Valid Percent \\
\hline Strongly Agree & 17 & 42.5 & 42.5 \\
\hline Agree & 14 & 35.0 & 35.0 \\
\hline Neutral & 9 & 22.5 & 22.5 \\
\hline Disagree & 0 & 0 & 0 \\
\hline Strongly Disagree & 0 & 0 & 0 \\
\hline
\end{tabular}


However, the results for the interaction variable showed that the majority of the participants' responses were between agree and neutral because there were seven students, who were studying Arabic online, did not prefer the method of using MALL in learning Arabic. This was the case because they had a difficulty in meeting with their classmates beyond the classroom. As online students, they lacked the opportunity of meeting with their peers faceto-face. Table 9 shows the participants' responses:

Table 9. Apps Help Me to Interact With My Peers in Class and Outside of Class

\begin{tabular}{|l|c|c|c|}
\hline \multicolumn{1}{|c|}{ Interaction } & Frequency & Percent & Valid Percent \\
\hline Strongly Agree & 4 & 10.0 & 10.0 \\
\hline Agree & 9 & 22.5 & 22.5 \\
\hline Neutral & 20 & 50.0 & 50.0 \\
\hline Disagree & 6 & 15.0 & 15.0 \\
\hline Strongly Disagree & 1 & 2.5 & 2.5 \\
\hline
\end{tabular}

One-way ANOVA was also used to look at whether there were statistically significant differences in the use of MALL apps technology in the learning of Arabic by non-native speaking students according to the 5Cs model. The results were statistically significant between the variable "I am satisfied with using mobile apps for Arabic learning" and the independent variables "age range" and "frequency of using the mobile apps." The $p$-value was 0.007 for "age range" and 0.000 for the "frequency of using the mobile apps." Both $p$-values were less than 0.05 , and this indicated a statistically significant difference between the variables.

There was also a statistically significant difference between the dependent variable "Apps can be accessed at anywhere at any time" and the independent variables "age range" and "educational level." The $p$-value was 0.000 for "age range" and 0.000 for the "educational level." Both were less than 0.05 , and this means there was a statistically significant difference between the mean values. This statistically significant difference was most likely detected because the majority of the participants were between 18-25 years old. People of this age range tend to be rather active users of technology and used the mobile apps several times in their learning, no matter if the students were graduate or undergraduate.

When asked if mobile apps are useful in learning Arabic, the results also revealed that there was a connection between the usefulness of apps and the frequency of using apps in learning Arabic. The many times the students used apps, it was useful in learning. The $p$-value was 0.029 , which is less than 0.05 for the "frequency of using the mobile apps." This result indicated a statistically significant difference between these variables.

The results also showed there was a correlation between user-friendly variable and the class level of learning Arabic, whether Arabic 101 or Arabic 102. Due to the many times the students used apps, it was easy for them to get used to practice with apps in learning. In both levels of Arabic, the students liked the user friendly-apps, as they helped them to practice more speaking scenarios and know about the Arabic culture. The $p$-value was 0.049 , which is less than 0.05 for the "Arabic class level." This result showed a statistically significant difference between these variables.

Moreover, there was a statistically significant difference between the dependent variable "I very much enjoyed using the mobile apps in my Arabic class this semester" and the independent variables "age range" and "frequency of using the mobile apps," The $p$-value was 0.014 for "age range" and 0.001 for the "frequency of using the mobile apps." Both were less than 0.05 and this indicated a statistically significant difference between these variables. Once again, this statistically significant difference was perhaps detected because the majority of the participants were young. They were eager to use their mobile devices for several different usages.

As for the method of preference, the results showed that $17.5 \%$ (seven participants) preferred the method of teaching without using the mobile apps in learning, but $80.0 \%$ (32 participants) preferred the method of teaching with using the mobile apps in learning. The missing data consisted of $2.5 \%$ because one participant did not respond to this question. The results revealed that the majority of participants preferred the method of teaching with using the mobile apps in learning. Table 10 shows the participants' responses. 
Table 10. "Without Mobile Apps" and "With Mobile Apps"

\begin{tabular}{|l|c|c|c|}
\hline \multicolumn{1}{|c|}{ Learning Preference } & Frequency & Percent & Valid Percent \\
\hline Method without mobile apps & 7 & 17.5 & 17.9 \\
\hline Method with mobile apps & 32 & 80.0 & 82.1 \\
\hline Missing data & 1 & 2.5 & \\
\hline
\end{tabular}

Fisher's Exact Test was used to measure the difference in mean between the teaching method's preference variable and the students' demographic information variables. Fisher's Exact Test was used to produce counts between two categorical variables (2X2) and to allow for trend analysis with conditional probabilities or crosstabs to determine if these variables were independent or related. As shown in Table 11, the Fisher's Exact Test revealed that there was a statistically significant difference between the dependent variable "Which method of teaching the students prefer" and the independent variable "Reason for Studying Arabic." The $p$-value was 0.016 for the Fisher's Exact Test, which was less than 0.05 .

Table 11. Reason for Studying Arabic: Fisher's Exact Test

\begin{tabular}{|l|c|c|c|c|c|}
\hline & Value & Df & $\begin{array}{c}\text { Asymp. Sig. } \\
\text { (2-sided) }\end{array}$ & $\begin{array}{c}\text { Exact Sig. } \\
\text { (2-sided) }\end{array}$ & $\begin{array}{c}\text { Exact Sig. } \\
\text { (1-sided) }\end{array}$ \\
\hline Likelihood Ratio & 8.441 & 1 & .004 & & \\
\hline Fisher's Exact Test & & & & .029 & .016 \\
\hline Linear-by-Linear Association & 5.783 & 1 & .016 & & \\
\hline N of Valid Cases & 39 & & & & \\
\hline
\end{tabular}

The Fisher's Exact Test also detected a statistically significant difference between the dependent variable "Which method of teaching the students prefer" and the "Arabic class format" variable, whether online or on-campus. All the on-campus and the majority of online students preferred the method of using MALL apps in learning Arabic, but only a few online students did not prefer it. The $p$-value was 0.002 for the Fisher's Exact Test, which is less than 0.05 . Table 12 exemplifies this statistically significant value.

Table 12. Arabic Class Format: Fisher's Exact Test

\begin{tabular}{|l|c|c|c|c|c|}
\hline & Value & Df & $\begin{array}{c}\text { Asymp. Sig. } \\
\text { (2-sided) }\end{array}$ & $\begin{array}{c}\text { Exact Sig. } \\
\text { (2-sided) }\end{array}$ & $\begin{array}{c}\text { Exact Sig. } \\
\text { (1-sided) }\end{array}$ \\
\hline Likelihood Ratio & 12.651 & 1 & .000 & & .002 \\
\hline Fisher's Exact Test & & & & & .002 \\
\hline Linear-by-Linear Association & 9.698 & 1 & .002 & & \\
\hline N of Valid Cases & 39 & & & & \\
\hline
\end{tabular}

The findings from quantitative (QUAN) data were very interesting and positive. The majority of students preferred the use of MALL apps when learning Arabic. Obviously, the mobile apps technology is available to use at any time from anywhere. This is the primary advantage that motivated educators and learners to shift to using MALL instead of computer assisted language learning (CALL). Therefore, the mobile learning method could be recommended for other instructors and learners who are interested in the language and culture. The participants represented a wide range of demographic factors, including ages, graduate and undergraduate status, online and on-campus students, and frequency of using mobile apps in learning Arabic.

The researcher believes that the use of the student-centered learning pedagogy and that giving students more speaking scenarios inside and outside the classroom will help educators and learners achieve their objectives. It will also help the student to acquire the language successfully [2]. The use of mobile learning aids the students in communicating in the language with their fellow students or with native speakers. It also helps them to compare their own native language with the target language that they are learning. By implementing the mobile learning pedagogy, the instructor can create an environment where students are able to learn more about other cultures and to connect with their instructors, classmates, and community members [2]. Based on their age range and how often they used the apps, the participants reported that they were satisfied with the quality of the apps for learning Arabic. They had positive perceptions about the mobile apps' efficiency. They reported that the apps were fun to use in learning. This finding supports such studies as [24, 41, 42, 38], which all claim that the use of mobile apps 
technology makes learning fun, valuable, and collaborative.

Additionally, the majority of the participants, whether undergraduate or graduate, strongly agreed that MALL apps can be accessed from anywhere at any time. This finding demonstrates Kukulska-Hulme's [28] point of view that mobile technologies have the advantage of anywhere and anytime. Students can access mobile apps to assist them with learning on the go or at home. The mobile apps functions as a private tutor to assist the learners at any time from any place. When asked if mobile apps were useful in learning Arabic, the highest percentage of students' responses was between strongly agree and agree. These positive perceptions match with the literature [6]. The findings also support the notion that mobile apps are user-friendly, which parallels previous mobile assisted language learning studies $[6,20]$. The findings were also consistent with previous research like $[6,25,41]$, which indicate that mobile technology is interesting to use when learning.

The researcher proposes that the students' ages play a vital role in the frequency of using the mobile apps in learning. The younger populations, the digital natives, like to use technology more often in their daily practices. This fact affects the learning pedagogy, as younger students are more likely to utilize technology because they may see it as fun, but the older generations may find it not useful in learning. Since there are many apps out there in learning foreign languages, some of them are for kids and others for adult learners; the researcher recommends that the selection and development of apps have to be based on the students' goals and ages. In addition, the factor "frequency of using the mobile apps" probably influenced the students' desire to continue using the mobile apps in learning Arabic. In this respect, the finding of this data analysis corresponded to previous studies [18, 43, 44], which revealed that there was a correlation between frequency and mobile learning.

Moreover, the findings also showed that there were not many differences between the online and on-ground students' perceptions. Their responses were not completely different. Most of the participants preferred the mobile apps method in learning. This finding is consistent with previous research that indicated that there were no significant differences in students' perceptions in either mode of study $[4,11,48]$. The students preferred the mobile learning method based on their reasons to study Arabic and their class mode, whether online or in-class.

\section{CONCLUSIONS}

Mobile technologies are increasing and growing very fast. This growing will promote the ability of mobile devices to present textbooks, encourage mobile learning, support with library research, and data collection procedure. The quick access to data wherever and whenever questions arise will lead administrators', faculty and learners' to change their teaching and learning techniques. Mobile learning approach is very useful in learning modern languages as technology makes the world a small village and help the students to connect with faculty and learners from other universities and countries quickly and efficiently.

Those who could benefit from the findings of this study are the educational administrators at institutions that offer instruction in Arabic, the instructors of Arabic, and the students who are learning Arabic in the United States. However, the ones who have the power to take action based on these findings are the instructors and administrators. Arabic teachers might find this study helpful as they seek to improve or modify the teaching methods they use in order to gain the best results in the learning process. The results of the study might also be of great value to communication software developers, apps programmers, mobile technology providers, and textbook writers. Business investors might also find this study helpful to guide their investments in the development of more mobile apps technologies for language learning purposes [2]. The limitations of the study include the number of participants who completed the questionnaire (40 students). They were selected from three small universities in the state of Pennsylvania. The Arabic program in these three schools was not big enough to recruit more students. The students were recruited from Arabic 101 (one online class and one on-ground class) and Arabic 102 (one online class and one on-ground class). There were not students from the Advanced levels of Arabic. Several other studies could be generated from this research. One study may focus on the teachers' perceptions on the use of mobile apps in learning Arabic as a second language. Another study may investigate the effectiveness of mobile assisted language learning (MALL) as a conversational tool in improving Arabic speaking proficiency. 


\section{REFERENCES}

1. Abdous, M., Camarena, M. M., \& Facer, B. R. (2009). MALL technology: Use of academic podcasting in the foreign language classroom. European for Computers Assisted Language Learning: UK.

2. Abedalla, R. (2015). Students' Perceptions of the Use of Mobile Applications Technology in Learning Arabic as a Second Language (Doctoral dissertation, Robert Morris University).

3. Al-Fahad, F. (2009). Students' attitudes and perceptions towards the effectiveness of mobile learning in King Saud University, Saudi Arabia. The Turkish Online Journal of Educational Technology; 8(2), 111-119. 4.

4. Ali, A., \& Elfessi, A. (2004). Examining students' performance and attitude s towards the use of information technology in a virtual and conventional setting. The Journal of Interactive Online Learning, 2(3).

5. Ally, M., \& Prieto-Blázquez, J. (2014). What is the future of mobile learning in education? Mobile Learning Applications in Higher Education [Special Section]. Revista de Universidad y Sociedad del Conocimiento (RUSC), 11(1), 142-151.

6. Almasri, R. (2013). The use of mobile technology in education by international students in United States universities: Perceptions regarding mobile applications for English language learning (Doctoral dissertation, Robert Morris University).

7. Alosh, M. (1991). International perspectives on foreign language teaching. Arabic Diglossia and Its Impact on Teaching Arabic as a Foreign Language. NTC Publishing Group, (pp. 121-137). Chicago, Illinois.

8. Ariew, R., \& Palmer, J. (2009). Learning culture and language through ICTs: Methods for enhanced instruction. Developing Hypertext Reading Materials for the Teaching of Arabic. Information Science Reference, (pp 5871). Hershey. NY.

9. Baleghizadeh, S. \& Oladrostam, E. (2010). The effect of mobile assisted language learning (MALL) on grammatical accuracy of EFL students. MEXTESOL Journal, 34(2).

10. Bayyurt, Y., Erçetin, G., \& Karataş, N. B. (2014). The stages in mobile-assisted language learning material development. Mobile as a Mainstream-Towards Future Challenges in Mobile Learning Communications in Computer and Information Science, 479, (pp.339-350). Springer International Publishing Switzerland.

11. Benson, A. D., Johnson, S. D., Taylor, G. D., Treat, T., Shinkareva, O. N., \& Duncan, J. (2005). Achievement in online and campus-based career and technical education (CTE) courses. Community College Journal of Research and Practice, 29, 369-394.

12. Beres, D. (2011). Mobile-assisted language learning from the student perspective: Encouraging effective language learning strategies outside of the classroom. In Facer, B. R. \& Abdous, M. (Eds.), Academic Podcasting and Mobile Assisted Language Learning: Applications and Outcomes, 93-110. IGI Global.

13. Cavus, N., \& Ibrahim, D. (2009). M-learning: An experiment in using SMS to support learning new English language words. British Journal of Educational Technology, 40(1), 78-91.

14. Chinnery, G. M. (2006). Going to the MALL: Mobile assisted language learning. Language Learning \& Technology, 10(1), 9-16.

15. Clary, D., Kigotho, M., \& Barros-Torning, M. (2013). Harnessing mobile technologies to enrich adolescents' multimodal literacy practices in middle years classrooms. Literacy Learning: The Middle Years, 21(3), 49-60

16. Corlet, D., Sharples, D., Bull, S. \& Chan, T. (2005). Evaluation of a mobile learning organizer for university students. Journal of Computer Assisted Learning, 21, 162-170.

17. Daniels, P. T., \& Bright, W. (1996). The World's Writing Systems. New-York: Oxford University Press.

18. DeWitt, D., Siraj, S., \& Alias, N. (2014). Collaborative mLearning: A module for learning secondary school science. Educational Technology \& Society, 17(1), 89-101.

19. Gamper, J., \& Knapp, J. (2002). A review of intelligent CALL systems. Computer assisted language learning (CALL): An International Journal, 15(4), 329-342.

20. Gilgen, R.G. (2004). Creating a mobile language learning environment. PowerPoint presentation presented at the Educause Midwest Regional Conference, Chicago, IL.

21. Jaradat, R. M. (2014). Students' attitudes and perceptions towards using m-learning for French language learning: A case study on Princess Nora University. International Journal of Learning Management Systems, 2(1), 33-44.

22. Kaye, A. S. (1987). The World's Major Languages: Arabic. Bernard Comrie. New York: Oxford University Press.

23. Kennedy, C., \& Levy, M. (2008). L'italiano al telefonino: Using SMS to support beginners' language learning. $\operatorname{ReCALL}, 20(3), 315-330$. 
24. Khaddage, F., Lattemann, C. \& Bray, E. (2011). Mobile apps integration for teaching and learning: (Are Teachers Ready to Re-blend?). In M. Koehler \& P. Mishra (Eds.), Proceedings of Society for Information Technology \& Teacher Education International Conference 2011 (pp. 2545-2552). Chesapeake, VA: AACE

25. Korkmaz, H. (2010). The effectiveness of mobile assisted language learning as a supplementary material for English teaching coursebooks (Master's Thesis, Ankara: Bilkent University).

26. Kukulska-Hulme, A. (2015). Language as a bridge connecting formal and informal language learning through mobile devices. Seamless learning in the age of mobile connectivity, 281-294.

27. Kukulska-Hulme, A. \& Shield, Lesley (2008). An overview of mobile assisted language learning: From content delivery to supported collaboration and interaction? The Open University, UK. ReCALL, 20(3), 271-289.

28. Kukulska-Hulme, A. (2006). Mobile language learning now and in the future. In Svensson, Patrik (Ed.). Fran vision till praktik: Sprakutbildning och Informationsteknik (From vision to practice: language learning and IT). Sweden: Swedish Net University (N"atuniversitetet), 295-310.

29. Lipinski, Edward (2001). Semitic languages outline of a comparative grammar (Orientalia Lovaniensia Analecta). $2^{\text {nd }}$ ed. Peeters Publishers and Department of Original Studies.

30. Liu, M., Navarrete, C. C., Maradiegue, E., \& Wivagg, J. (2014). Mobile learning and English language learners: A Case study of using iPod touch as a teaching and learning tool. Journal of Interactive Learning Research, 25(3).

31. Miangah, T. M., \& Nezarat, A. (2012). Mobile-assisted language learning. International Journal of Distributed and Parallel Systems (IJDPS), 3(1), 309-319.

32. Naismith, L., Lonsdale, P., Vavoula, G., \& Sharples, M. (2004). Literature review in mobile technologies and learning. Educational Technology Research Group, University Birmingham.

33. Nydell, M. K. (2012) Understanding Arabs: A Contemporary Guide to Arab Society (5 ${ }^{\text {th }}$ ed). Boston, London: Intercultural Press.

34. Pachler, N., Cook, J., \& Bradley, C. (2009). "I don't really see it": Whither case-based approaches to understanding off-site and on-campus mobile learning? In G. Vavoula, N. Pachler \& A. Kukulska-Hulme (Eds.), Researching mobile learning, (pp. 77-96). Bern: Peter Lang.

35. Padley, B. (2012). Websites vs. Mobile Apps: A content analysis of Tampa Bay's News. Applied Research Project submitted for completion of M.A. in Journalism, University of South Florida St. Petersburg.

36. Paullet, K., Pinchot, J. L., Douglas, D., \& Rota, D. R. (2011). Mobile technology: Plugged in and Always on. Issues in Information Systems, XII(1), 141-150.

37. Pinchot, J. L., Paullet, K. L., \& Rota, D. R. (2011). How mobile technology is changing our culture. Journal of Information Systems Applied Research Systems, 4(1), 39-48.

38. Rossing, J. P., Miller, W. M., Cecil, A. K., \& Stamper, S. E. (2012). iLearning: The future of higher education? Student perceptions on learning with mobile tablets Journal of the Scholarship of Teaching and Learning, $12(2), 1-26$.

39. Shaalan, K. F., \& Talhami, H. E. (2006). Arabic error feedback in an online Arabic learning system. A. Gelbukh (Ed.). Advances in natural language processing. Research in computing science 18, 203-212.

40. Sharples, M., Taylor, J., \& Vavoula, G. (2007). A theory of learning for the mobile age. In R.Andrews \& C. Haythornthwaite (Eds.). The sage handbook of e-learning research (pp. 221 247). London: Sage.

41. Shockoe. (2014). Mobile applications development: Move over, Rosetta Stone: Mobile language apps make learning fun. Retrieved from http://www.shockoe.com/blog/move-over-rosetta-stone-mobile-language-appsmake-learning-fun/

42. Steel, C. H. (2012). Fitting learning into life: Language students' perspectives on the benefits of using mobile apps. In M. Brown, M. Hartnett \& T. Stewart (Eds.), Future challenges, sustainable future, proceedings of ascilite conference Wellington 2012, (pp. 875-880).

43. Stockwell, G. (2013).Tracking learner usage of mobile phones for language learning outside of the classroom. CALICO Journal, Learner-Computer Interaction in Language Education: A Festschrift in Honor of Robert Fischer.

44. Stockwell, G. (2007). Vocabulary on the move: Investigating an intelligent mobile phone-based vocabulary tutor. Computer Assisted Language Learning, 20(4), 365-383.

45. Tai, Y. (2012). Contextualizing a MALL: Practice Design and Evaluation. Educational Technology \& Society, 15(2), 220-230. 220 ISSN

46. Techopedia. (2013). Mobile Application. Retrieved from http://www.techopedia.com/definition/2953/mobile-application-mobile-app 
47. Todd, R. W., \& Tepsuriwong, S. (2008). Mobile mazes: Investigating a mobile phone game for language learning. Computer Assisted Language Learning, 10(1).

48. Ury, G., McDonald, M., McDonald, G., \& Dorn, B. (2005). Student performance online Vs. on-ground: A statistical analysis of IS Courses. Proc ISECON 2005, v22 (Columbus OH): $\$ 3162$ (refereed).

49. Valarmathi, K. E. (2011). Mobile assisted language learning. Journal of Technology for ELT, 2(2).

50. Versteegh, K. (2014). The Arabic Language. Edinburgh University Press (2 ${ }^{\text {nd }}$ ed.).

51. Viberg, O., \& Grönlund, Å. (2012). Mobile assisted language learning: A literature review. $m L e a r n, C E U R$ Workshop Proceedings, 955, 9-16.

52. Yamaguchi, T. (2005). Vocabulary learning with a mobile phone. Program of the $10^{\text {th }}$ Anniversary Conference of Pan-Pacific Association of Applied Linguistics, Edinburgh, UK.

53. Younus, A. D. (2014). Investigation of a mobile government a case study in Iraq. Nicosia. Retrieved from http://library.neu.edu.tr/Neutez/6319424922.pdf 